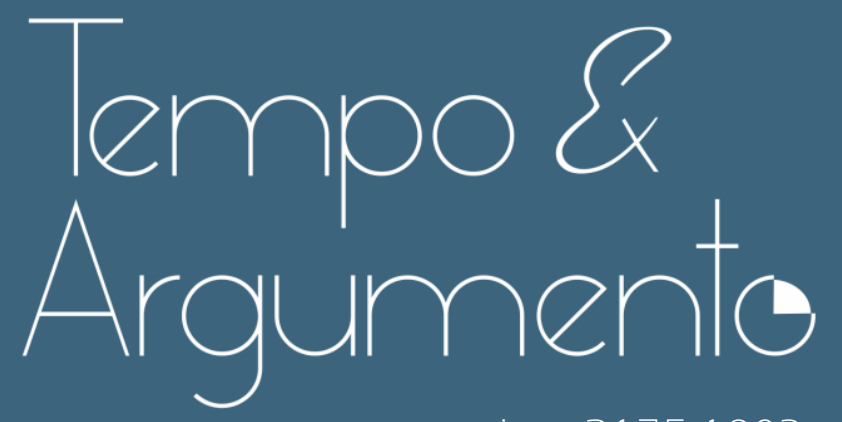

e-issn 2175-1803

\title{
Teoria de gênero e ideologia de gênero: cenário de uma disputa nos 25 anos da IV Conferência Mundial das Mulheres
}

• Géssica Guimarães

Doutora em História Social da Cultura pela Pontifícia Universidade Católica do Rio de Janeiro (PUC-Rio). Professora Adjunta do Departamento de História e do Programa de Mestrado Profissional em Ensino de História da Universidade do Estado do Rio de Janeiro (UERJ).

Rio de Janeiro, RJ - BRASIL

lattes.cnpq.br/1763431207940049

gessicagg@yahoo.com.br

(i) orcid.org/0000-0002-2369-8646

Para citar este artigo:

GUIMARÃES, Géssica. Teoria de gênero e ideologia de gênero: cenário de uma disputa nos 25 anos da IV Conferência Mundial das Mulheres. Tempo e Argumento, Florianópolis, v. 12, n. 29, e0 107, jan./abr. 2020

doi http://dx.doi.org/10.5965/2175180312292020e0 107 


\title{
Teoria de gênero e ideologia de gênero: cenário de uma disputa nos 25 anos da IV Conferência Mundial das Mulheres
}

\begin{abstract}
Resumo
Este artigo tem como eixo principal a investigação acerca das diferenças entre a teoria de gênero e a ideologia de gênero. O objetivo consiste em historicizar o significado e conteúdo atribuído tanto à teoria de gênero quanto à ideologia de gênero, a fim de compreender os desdobramentos científicos, políticos e pedagógicos de cada uma das perspectivas sobre as relações de gênero em nossa sociedade. Identificamos a afirmação do gênero como uma categoria analítica por volta da década de 1980, entre historiadoras e cientistas sociais ligadas aos estudos sobre mulheres e à história das mulheres, que buscavam a compreensão das relações entre homens e mulheres por um viés histórico que destacasse as relações de poder que reiteravam estruturas de opressão. Já a ideologia de gênero surgiu como uma resposta ao movimento feminista que ganhava grande amplitude política, notável pela importância da IV Conferência Mundial das Mulheres, realizada em 1995 pela ONU, em Pequim, mas que rapidamente também se tornou uma perseguição aos movimentos que questionam a heterossexualidade compulsória, conjugando em suas pautas o ataque a movimentos que desafiassem a normatividade do patriarcado. Por fim, nos interessa indicar como ambas as concepções podem afetar o ensino de história, pois entendemos que o estudo crítico acerca das relações de gênero pode contribuir para a construção de uma educação democrática.
\end{abstract}

Palavras-chave: Teoria de gênero. Ideologia de gênero. IV Conferência Mundial das Mulheres. Ensino de História. História das mulheres.

\section{Gender theory and gender ideology: scenario of a struggle after 25 years of the IV World Conference on Women}

\begin{abstract}
This paper aims to investigate the distinctions between Gender theory and Gender ideology. Our main goal consists in historicizing the meaning and the content given to Gender theory and Gender ideology, in order to understand the scientific, political and pedagogical developments of each of the perspectives about the gender relations in our society. We identified the affirmation of gender as an analytical category around the 1980s, between historians and social scientists linked to women's studies and women's history that sought to understand the relations between men and women by a historical bias, which highlighted the power relations that reiterated structures of oppression. Gender ideology emerged as a response to the feminist movement that was gaining great political strengthening, expressed in the importance of the IV World Conference on Women held in 1995 by the UN in Beijing, but it also quickly became a persecution of movements that question compulsory heterosexuality, combining in its agenda the attack on movements that challenged the normativity of patriarchy. Finally, we are interested in indicating how both conceptions can affect the History teaching, because we understand that the critical study about gender relations can contribute to the construction of a democratic education.
\end{abstract}

Keywords: Gender theory. Gender ideology. IV World Conference on Women. History teaching. History of women. 

"Em uma cultura de dominação, todo mundo é socializado para enxergar violência como meio aceitável de controle social."

(bell hooks¹. O feminismo é para todo mundo)

\section{Feminismo para o quê ou para quem?}

O cenário político mundial e brasileiro tem apontado à proeminência dos movimentos das mulheres e antirracistas como uma das mais importantes vertentes de mobilização social. Entre eles, as diversas manifestações do feminismo têm ressaltado a tomada de consciência de grupos bastante distintos de mulheres acerca das opressões estruturais às quais elas têm sido submetidas ao longo dos séculos. Reivindicações por maior participação política; direito irrestrito ao corpo; a condenação do racismo, da homofobia e da transfobia; direito ao espaço público e à educação e a luta contra a violência endereçada às mulheres são algumas das pautas presentes nos diversos coletivos e grupos políticos nos quais as mulheres têm encontrado acolhimento para suas reivindicações.

Contudo, na sociedade brasileira parece imperar um mal-entendido produzido de forma deliberada ou por desconhecimento - sobre as reivindicações de caráter feminista, constantemente confundidas com o ataque a instituições como a família, o casamento e a Igreja. Como bem nos esclarece a teórica norte-americana bell hooks, o feminismo como movimento político e como base para a crítica da sociedade e da cultura consiste na denúncia da existência de privilégios em nossa sociedade fundamentados na diferença entre os sexos e, por isso, sustenta como principal proposta o combate a todas as formas de sexismo. Portanto, seria um equívoco conceber o feminismo como um movimento anti-homem ou antifamília. 
A luta feminista tem como base a percepção de que inúmeras desigualdades e violências são geradas em nossa sociedade por causa das diferenças produzidas a partir das relações de gênero - o masculino e o feminino - e identifica o combate contra tais opressões como um imperativo para a constituição de sociedades democráticas (HOOKS, 2018). Decerto que o mais apropriado seria desde já nos referirmos aos movimentos das mulheres como plurais e aos feminismos como diversos. Tal variedade não se encerra em disputas teóricas ou experiências conjunturais, uma vez que o principal vetor das dissidências e multiplicidade de concepções no interior do movimento feminista é resultado do encontro das manifestações contrárias à dominação sexista com outros marcadores de desigualdade social, principalmente a raça e a classe, como tem nos apontado Angela Davis (2016) desde a publicação de seu Mulheres, raça e classe, em 1981. Portanto, seguindo a proposta analítica da professora da faculdade de direito da Universidade da Califórnia em Los Angeles, e uma das principais estudiosas sobre a teoria crítica da raça, Kimberlé Williams Crenshaw², assinalamos a transformação significativa que o conceito de interseccionalidade tem operado na prática dos movimentos feministas e no pensamento crítico como um todo (AKOTIRENE, 2019).

Ademais, as expressões dos feminismos em nossa atualidade têm cada vez mais sublinhado a importância do protagonismo político e científico daquelas mulheres que são as principais afetadas pela interseção de tantos traços de exclusão social. Ao reivindicar o "lugar de fala" desses sujeitos, como nos explica a filósofa brasileira Djamila Ribeiro, o que se exige é o reconhecimento de que a exclusão também é de ordem política e epistemológica, e que a criação das oportunidades para a fala faz parte de uma militância menos interessada em apresentar essas mulheres e os problemas por elas enfrentados e mais empenhada em criar espaços em que essas mesmas mulheres possam realmente falar e serem ouvidas (RIBEIRO, 2017).

Artigo publicado no site Geledés: https://www.geledes.org.br/mapeando-as-margensinterseccionalidade-politicas-de-identidade-e-violencia-contra-mulheres-nao-brancas-dekimberle-crenshaw\%E2\%80\%8A-\%E2\%80\%8Aparte-1-4/. Acesso em: 10 maio 2019. 
Teoria de gênero e ideologia de gênero: cenário de uma disputa nos 25 anos da IV Conferência Mundial das Mulheres

Desde 2011/2012², podemos perceber na sociedade brasileira manifestações em torno das diversas pautas feministas e a crescente mobilização de diferentes grupos de mulheres por seus direitos. Na vanguarda dessa mobilização, hoje atuam mulheres negras, indígenas, faveladas, lésbicas, mães que tiveram seus filhos e filhas mortos pela violência do Estado e que nos fazem lembrar o quanto pautas históricas como o direito ao voto e a conquista do mercado de trabalho ainda não foram suficientes para transformar suas realidades. Como tem sido apontado pela filósofa Sueli Carneiro, a opressão contra as mulheres negras se alicerça em práticas sociais de longa data que se estruturam em um biopoder e em uma ontologização da exploração e da marginalização, resultando em processos de exclusão social e política, pauperização econômica, violência e atentado contra a vida e apagamento de suas memórias, histórias e saberes através de um verdadeiro epistemicídio (CARNEIRO, 2005).

Portanto, pensar as mulheres como um grupo heterogêneo e buscar a compreensão de como as diferentes sociedades interpretam as manifestações físicas do sexo e quais papéis sociais são atribuídos aos gêneros historicamente, pode contribuir para o entendimento das estruturas de poder de longa duração, além de nos permitir vislumbrar um horizonte no qual possamos superar tal quadro de opressões. Para que essa expectativa se realize, defendemos a importância de uma educação que promova a solidariedade entre os indivíduos, a partir do reconhecimento de processos históricos de exploração e segregação. Outrossim, identificamos como primordial para a constituição de uma sociedade verdadeiramente democrática o compromisso do Estado e de seus agentes como promotores de justiça social, através do direito à vida, à educação, ao trabalho, à participação política e a tantos outros direitos que ainda hoje são subtraídos de inúmeras mulheres brasileiras.

\footnotetext{
Esta periodização é totalmente provisória, e sem o menor objetivo de apagar a importante história dos feminismos brasileiros nas décadas anteriores. Tomamos como referência a organização da primeira "Marcha das vadias", em 4 de junho de 2011, em São Paulo. Esse movimento é significativo por trazer ao espaço público uma série de reivindicações dos movimentos feministas como a criminalização da violência contra a mulher, a legalização do aborto, o direito ao corpo e à sexualidade, bem como pela reação conservadora que se levantou contra a manifestação desde sua primeira edição. Mas talvez ainda mais importante seja lembrar que em 2012 foi aprovada a lei conhecida como "PEC das domésticas", levantando um grande debate sobre o papel da mulher negra na sociedade brasileira e a mobilização do movimento das mulheres negras em defesa de seus direitos. Também consideramos a importante e ainda pouco estudada participação das mulheres nas jornadas de 2013
} 


\section{Gênero como categoria analítica}

Para melhor historicizar nossa questão, recorremos a três artigos publicados pela historiadora estadunidense Joan Scott (em 1989, 1992 e 2010). Embora suas conclusões tenham como fonte de observação o movimento feminista e a comunidade acadêmica norte-americana, ainda assim suas considerações podem nos fornecer linhas gerais para pensar o surgimento da teoria de gênero e a emergência do discurso da ideologia de gênero nas últimas décadas. Nos dois primeiros artigos citados, nos é narrada a relação inaugural entre o movimento feminista nos anos 1960, nos Estados Unidos, e o surgimento dos "Women studies" nas universidades e sua subsequente influência sobre a emergência de uma "história das mulheres". bell hooks (2018) também destaca a relação direta entre a mobilização feminista das décadas de 1960 e 1970 e a institucionalização de grupos de estudos e de pesquisas sobre as questões que atravessavam a vida das mulheres, num processo de academicização desses debates e certo afastamento das ruas.

Disso, podemos inferir que a "história das mulheres" surgiu antes da teorização acerca da categoria de gênero, em um movimento historiográfico e político de denúncia dos silenciamentos e apagamentos das mulheres nas narrativas sobre o passado. Suely Gomes Costa nos informa que também na tradição francesa é possível verificar a estreita relação entre os estudos sobre as histórias das mulheres e a mobilização política naquela sociedade (COSTA, S., 2009, p. 187), uma vez que a história dos homens já estava escrita, cabia agora escrever a história das mulheres. Contudo, no final da década de 1980, Scott, historiadora feminista, concluiu que:

A reação da maioria dos/as historiadores/as não feministas foi o reconhecimento da história das mulheres e, em seguida, seu confinamento ou relegação a um domínio separado ("as mulheres tiveram uma história separada da dos homens, em conseqüência deixemos as feministas fazer a história das mulheres que não nos diz respeito"; ou "a história das mulheres diz respeito ao sexo e à família e deve ser feita separadamente da história política e econômica"). (SCOTT, 1995, p. 74).

No artigo sobre a história das mulheres, que compõe a coletânea organizada por Peter Burke, publicada no Brasil em 1992, a historiadora destaca 
Teoria de gênero e ideologia de gênero: cenário de uma disputa nos 25 anos da IV Conferência Mundial das Mulheres

uma ambiguidade a respeito dos sentidos da história das mulheres na historiografia norte-americana, ao mesmo tempo considerada apenas como um apêndice da história estabelecida, mas também um "deslocamento radical dessa história". É desse lugar incômodo que pôde ganhar legitimidade a categoria de gênero, uma vez que aponta para a preocupação com as relações desiguais socialmente estabelecidas entre aqueles que são identificados com o feminino e o masculino, bem como busca maior aceitação na comunidade acadêmica, através da hipotética neutralização da motivação política da análise, na intenção subterrânea de que a política concedesse lugar à teoria ${ }^{4}$. Ainda nesse mesmo artigo, Scott avalia que "A emergência da história das mulheres como um campo de estudo envolve, nesta interpretação, uma evolução do feminismo para as mulheres e daí para o gênero; ou seja, da política para a história especializada e daí para a análise."5 (SCOTT, 1992, p. 65).

Em “Gênero: uma categoria útil para a história”, artigo publicado em 1989, Scott teorizou sobre a categoria de gênero e considerou sua pertinência para o trabalho das historiadoras e dos historiadores, uma vez que as pesquisas categorizadas como "história das mulheres" haviam sofrido um processo de guetificação na historiografia norte-americana, pois muitos intelectuais buscavam na utilização da categoria de gênero maior legitimidade para seus trabalhos ao reivindicar implicitamente imparcialidade axiológica. De acordo com Suely Costa (2009, p. 187), Michele Perrot e outras intelectuais francesas também concluíram que "examinar a opressão ou a rebelião é insuficiente para apreender a dominação como uma relação dialética”. Como uma ferramenta heurística, gênero teria um caráter analítico, que permitiria às pesquisadoras e aos pesquisadores abordar as questões entre o feminino e o masculino através de

\footnotetext{
4 A menção à ideia de história das mulheres como "suplemento" à história já estabelecida, sugerida ironicamente por Virginia Woolf e brilhantemente invocada por Scott, nos atenta para o caráter supérfluo e ao mesmo tempo desconcertante que a história das mulheres pode exercer tanto na produção científica como em seu impacto político-social.

${ }^{5}$ Scott assinala, entretanto, que o fato da história das mulheres ter se tornado um campo de estudos acadêmicos, bem como a ampla adesão de pesquisadores à categoria de gênero, não significou o desaparecimento do feminismo como um movimento político, como uma narrativa linear e superficial dessas questões poderia sugerir. Inclusive porque muitos trabalhos identificados com a história das mulheres e a análise de gênero têm se preocupado com pautas históricas do movimento feminista. "Mais do que postular uma simples correlação, precisamos pensar sobre este campo como um estudo dinâmico na política da produção do conhecimento." (SCOTT, 1992, p. 65-66).
} 
termos relacionais, isto é, considerando mulheres e homens no tempo, sua historicidade e como as relações entre mulheres e homens têm implicações na escrita da história. Ainda segundo Costa (2009, p. 188), "é possível intuí-lo (o conceito de gênero) como um código-chave inventado para superar impasses que a história das mulheres havia chegado", sobretudo no que diz respeito às relações travadas no mundo privado.

A utilização de gênero como uma categoria para a análise das relações sociais fundamentadas nas diferenças entre os sexos consiste na rejeição de definições fixas e permanentes, que tendem a expressar a relação entre mulheres e homens de maneira binária. Seguindo tal proposta de trabalho, os historiadores deveriam afastar-se de interpretações baseadas em concepções essencialistas do que seria o homem e a mulher e adotar uma postura intelectual que priorizasse a historicização do que significa ser mulher e homem em cada tempo e sociedade. Não menos importante é a advertência de Joan Scott (1992), quando assinala que a utilização do termo "mulher" como categoria analítica tornou-se bastante questionada, principalmente pela conotação universalista que ele expressa. Em outras palavras, foi a percepção da diferença no seio da desigualdade que despertou nos analistas o interesse por salientar a pluralidade de existências contidas na categoria "mulheres", bem como a incidência de variados níveis de opressão. Vejamos como a autora compreende a inserção do termo - gênero - entre os estudos acadêmicos:

A palavra indicava uma rejeição do determinismo biológico implícito no uso de termos como "sexo" ou "diferença sexual". O termo "gênero" enfatizava igualmente o aspecto relacional das definições normativas da feminilidade. Aquelas que estavam preocupadas pelo fato de que a produção de estudos sobre mulheres se centrava nas mulheres de maneira demasiado estreita e separada utilizaram o termo "gênero" para introduzir uma noção relacional em nosso vocabulário analítico. Segundo esta visão, as mulheres e os homens eram definidos em termos recíprocos e não se poderia compreender qualqur um dos sexos por meio de um estudo inteiramente separado. (SCOTT, 1995, p. 72).

Em Calibã e a bruxa, a historiadora italiana Silvia Federici (2017) empreende uma análise sobre a acumulação primitiva de capital, na passagem da Idade Média para a Idade Moderna europeia, e tem como tese central a relação entre 
o controle dos corpos femininos e a caça às bruxas como fenômeno fundamental na transformação da função social das mulheres como reprodutoras da vida e mantenedoras da engrenagem no sistema que nascia. A pesquisa e, sobretudo, a narrativa construída pela autora, nos revela uma história que não é apenas das mulheres, mas que tem em seu cerne o controle da fecundidade e da procriação como elementos constitutivos da consolidação do sistema capitalista.

A fim de conferir à categoria de gênero sua força analítica, a historiadora estadunidense recorre ao conceito foucaultiano de poder e ao conceito derridiano de desconstrução. De Foucault, Scott (1995, p. 86) aplica a noção de poder como "[...] constelações dispersas de relações desiguais, discursivamente constituídas em "campos de forças" sociais". Já como atitude intelectual desconstrucionista, busca em Derrida a rejeição do caráter fixo e permanente da oposição binária, por meio da historicização e da desconstrução dos termos da diferença sexual. Isso significa “[...] analisar, levando em conta o contexto, a forma pela qual opera qualquer oposição binária, revertendo e deslocando sua construção hierárquica, em vez de aceitá-la como real ou auto-evidente ou como fazendo parte da natureza das coisas." (SCOTT, 1995, p.84).

Em Problemas de gênero, livro publicado pela filósofa Judith Butler, em 1990, o questionamento é lançado sobre a validade epistemológica da categoria de "gênero", atentando para a constatação de que se o gênero é uma construção histórica, cujos significados não são estáveis, porque estão sujeitos a arranjos sociais e à atribuição de sentidos a partir de disputas travadas entre os indivíduos, a categoria “sexo”, por sua vez, também não deveria ser utilizada como se comunicasse um significado definitivo. Segundo a tese sustentada por Butler, nossa sociedade está marcada pela hierarquia de gênero e pela heterossexualidade compulsória. A filósofa destaca que, contudo, o sexo deveria ser pensado como um ato performático, construído inclusive através da linguagem. Uma vez que é na ação que se constitui o sentido e expressão do gênero, e como não há sujeito anterior à ação, é no ato performático que se funda a própria caracterização do sexo e do gênero. Vejamos como a autora nos desafia o pensamento: "Ser mulher constituiria um "fato natural" ou uma 
performance cultural, ou seria a naturalidade constituída mediante atos performativos discursivamente compelidos, que produzem o corpo no interior das categorias de sexo e por meio delas?” (BUTLER, 2015, p. 9).

Sem descartar a categoria de gênero, Butler complexifica ainda mais a questão ao propor que a compreensão que cada sociedade tem do sexo deve ser analisada como uma construção histórica, que ganha concretude através da performance do sujeito que interpreta as relações de gênero, ou seja, o feminino e o masculino. Na proposição radical de Butler, o sexo como um dado natural nunca existiu, todas as relações sempre foram de gênero, isto é, interpretações sociais acerca do feminino e do masculino. Na sua compreensão, "A complexidade do conceito de gênero exige um conjunto interdisciplinar e pósdisciplinar de discursos, com vistas a resistir à domesticação acadêmica dos estudos sobre gênero ou dos estudos sobre as mulheres, e a radicalizar a noção de crítica feminista." (BUTLER, 2015, p. 13). O pensamento da filósofa e a ampliação dos debates em torno da "Teoria Queer" metade da década de 1990 e início dos anos 2000, provocou uma mudança significativa na maneira como a sociedade passou a compreender e reagir aos debates acerca da teoria de gênero.

\section{Ideologia de gênero}

Em artigo publicado em 2010, no qual Joan Scott mais uma vez defende a utilidade da categoria de gênero para a história, a historiadora reconhece que os desdobramentos do processo narrado acima contribuíram para uma nova politização em torno da categoria gênero. Dessa vez, tendo o enfoque não apenas nos estudos sobre as condições de vida das mulheres e suas reivindicações, mas também nos debates sobre a heteronormatividade, a homossexualidade, a transgeneridade, entre outros. Peço licença para a longa citação, que se justifica por ser esse relato deveras elucidativo:

\footnotetext{
${ }^{6}$ Campo de estudos que estuda os comportamentos que colocam em xeque a ideia de binarismo e normatividade nas relações de gênero.
} 
De fato, para algumas pessoas, gênero se tornou uma maneira educada de referir a qualquer coisa relacionada a sexo, enquanto sexo foi reservado para os atos físicos de fazer amor e/ou copular. Mas para outros, gênero tinha implicações radicais que precisam ser interrompidas. Esse foi o caso no prelúdio da Quarta Conferência Mundial sobre Mulheres das Nações Unidas, em Pequim, China em 1995. Nas semanas anteriores à reunião convocada, um subcomitê da Câmara dos Representantes dos Estados Unidos realizou audiências nas quais congressistas republicanos e delegados de grupos pelo direito à vida assinalaram as implicações subversivas do "gênero". Os oradores advertiram que valores da moralidade e da família estavam sob ataque por aqueles que acreditavam que possam existir ao menos cinco gêneros (homem, mulher, homossexuais, bissexuais e transexuais). E eles insistiram que o programa das Nações Unidas para a Conferência de Pequim havia sido "sequestrado" por "feministas do gênero, que acreditam que tudo que nós pensamos que é natural, incluindo a masculinidade e a feminilidade, maternidade e paternidade, heterossexualidade, casamento e família, são apenas manipulações criadas culturalmente, elaboradas por homens para oprimir as mulheres. Essas feministas afirmam que tais papeis foram socialmente construídos e são portanto sujeitos a mudança'. ' (SCOTT, 2010, p. 225, grifos nossos).

Giovanna Marafon e Marina Castro e Souza, ambas as professoras da Faculdade de Educação da Baixada Fluminense (FEBF-UERJ), analisaram a genealogia do discurso da ideologia de gênero e encontraram as mesmas evidências que Joan Scott: uma crescente mobilização conservadora por volta da metade da década de 1990. Além disso, também destacam a atuação do Vaticano na organização de uma ofensiva contra os debates suscitados pela teoria de gênero, com objetivos nítidos de confirmar a "naturalização da ordem

\footnotetext{
Tradução livre. Segue o trecho original: "Indeed for some people, gender became a polite way of referring to anything that had to do with sex, while sex was reserved for physical acts of lovemaking and/or copulation. But for others, gender had radical implications that needed to be stopped. This was the case in the prelude to the United Nations Fourth World Conference on Women, held in Beijing, China in 1995. In the weeks before the meeting convened, a subcommittee of the US House of Representatives held hearings at which republican congressmen and delegates from right-to-life groups pointed to the subversive implications of "gender." The speakers warned that morality and family values were under attack by those who believed that there might be as many as five genders (men, women, homosexuals, bisexuals and transsexuals). And they insisted that the UN program for the Beijing Conference had been hijacked by "gender feminists, who believe that everything we think of as natural, including manhood and womanhood, femininity and masculinity, motherhood and fatherhood, heterosexuality, marriage and family, are only culturally created 'fixes,' originated by men to oppress women. These feminists profess that such roles have been socially constructed and are therefore subject to change."” (SCOTT, 2010, p. 225).

8 Além da Conferência de Pequim, as autoras também citam os debates na Conferência Internacional sobre População, no Cairo, em 1994
} 
sexual centrada na dominação masculina e na matriz heterossexual." (MARAFON; SOUZA, 2018, p. 76). Se expandindo para além da reação católica, a "ideologia de gênero" tornou-se receptáculo e transmissora de variadas concepções reacionárias, que utilizam a retórica dos valores morais em nome do combate a qualquer forma de reivindicação dos direitos das mulheres e dos sujeitos cuja orientação sexual e identidade de gênero desafiem a heteronormatividade estabelecida.

Também em um esforço genealógico, Sonia Corrêa fez um breve histórico de algumas das principais conferências organizadas pelas Nações Unidas na década de 1990 e destacou que na ECO 92 (Rio de Janeiro) gênero não foi utilizado como uma categoria para se referir às questões relacionadas às pautas das mulheres. Como resultado dos debates ocorridos na Conferência sobre o Meio Ambiente, seria perceptível a adoção de um vocabulário que se pretendia neutro - por meio da afirmação da igualdade entre os sexos - e a atuação conservadora através da concepção dos direitos reprodutivos alicerçados em critérios classistas, reveladores da manutenção de propostas de controle populacional em áreas mais pobres do planeta. Corrêa nos lembra de que a adoção da palavra gênero em documentos internacionais ocorreu pela primeira vez na Conferência das Populações do Cairo (1994). Já em 1995, na IV CMM , o uso da categoria teria alcançado repercussão a ponto de motivar tamanha investida da Igreja Católica e demais setores conservadores da sociedade em combate às "políticas de gênero". Vejamos o relato da pesquisadora:

Nos debates oficiais da Eco 92, nem gênero, nem sexualidade, nem direito ao aborto estiveram em pauta. O Documento do Rio incluía a definição clássica de igualdade entre os sexos e a tensão negocial se deu em torno a questões que hoje podem parecer muito prosaicas: o direito ao planejamento familiar e o termo "saúde reprodutiva" que pouco antes havia adentrado a conversação entre estados membros da ONU pelas mãos da OMS. Por mais convencional que possa parecer, essa foi a pauta que suscitou ataques e manobras políticas por parte dos representantes da Santa Sé, que reativaram a controvérsia histórica Norte vs. Sul em torno a políticas de controle populacional, produzindo uma oposição discursiva entre pobreza e direito ao desenvolvimento, de um lado, e controle da

${ }_{9}$ IV Conferencia Mundial das Mulheres, ocorrida em Pequim. 
fecundidade de outro. Esse jogo foi facilitado pela posição de algumas redes ambientalistas globais que, na preparação para o Rio de Janeiro, haviam defendido o controle demográfico como medida necessária para proteção da natureza. (CORRÊA, 2018, p. $6-7)$.

Mesmo assinalando tal concepção sobre os direitos reprodutivos na Conferência sobre o Meio Ambiente no Rio de Janeiro, que reforça o traço de colonialidade nas relações entre os países do norte e do sul global, a autora considera que na Conferência do Cairo, quando debatidos os problemas das populações do planeta, a utilização de gênero como substituição a status das mulheres, consistiu em uma vitória, pois possibilitou que o foco do debate não estivesse restrito à fecundidade, mas que fossem destacadas as relações de poder alicerçadas na desigualdade fundada na concepção do feminino e do masculino como um dado biológico e natural.

Assim como Scott, a pesquisadora brasileira também relata a investida em reuniões preparatórias para Pequim contra a categoria de gênero, imprimindo ao debate um "colcheteamento" da palavra. Colocar a palavra gênero entre colchetes significava afirmar a existência de um problema, ou pelo menos acusar que esta havia perdido seu caráter consensual. Em um relato de sua participação nos debates em preparação para a Conferência de Pequim, Corrêa nos conta que:

Numa das salas de trabalho, assisti um delegado do Sudão exigir, vigorosamente, o "colcheteamento" da palavra e ser apoiado por outros países islâmicos, sem que a coordenadora da sessão conseguisse conter seu longo e agressivo discurso. Nessa cena, as mãos nem tão invisíveis do vaticano eram detectáveis, pois embora a Santa Sé não tenha se manifestado, as delegações de Honduras, Nicarágua e El Salvador, seus aliados fiéis, apoiaram a posição sudanesa. (CORRÊA, 2018, p. 8).

Seguindo a seara aberta pelas pesquisadoras supracitadas, fui à busca dos documentos elaborados na Conferência de Pequim para uma política internacional para as mulheres e a contrapartida preparada pelo Vaticano. Antes mesmo da realização da IV CMM, em junho de 1995, o Vaticano tornou pública a Carta do Papa João Paulo /l às mulheres, endereçada às mulheres como categoria universal, bem como aos episcopados. No primeiro item do documento, João Paulo II revela que sua motivação consiste na aproximação da Conferência 
de Pequim, que seria realizada em setembro do mesmo ano e, no final da carta, propõe que as comunidades episcopais se dediquem "a fazer do ano em curso ocasião para uma profunda aç̧ão de graças ao Criador e ao Redentor do mundo precisamente pelo dom de um bem tão grandecomo é o da feminilidade." (VATICANO, 1995, grifo do autor). Podemos verificar como a Igreja Católica reivindica para si a definição do que seria a feminilidade e o domínio no delineamento do campo de atuação das mulheres na vida privada e social.

Característica marcante do papado de Karol Józef Wojtyla, que reconheceu publicamente erros históricos da Igreja como o silenciamento por décadas sobre o Holocausto de judeus na Segunda Guerra Mundial, bem como as atrocidades praticadas pela Inquisição, João Paulo II reconheceu o processo histórico de dominação, de marginalização e de violência imposto às mulheres nas mais diversas áreas do planeta durante séculos. Contudo, esse esforço empático não é acompanhado por uma análise crítica sobre as razões de tantas opressões. Uma vez enunciadas as agruras enfrentadas pelas mulheres e realizadas as felicitações por suas conquistas e contribuições para o desenvolvimento de suas comunidades e, até mesmo, para a humanidade - sim, o reconhecimento da importância da ação das mulheres para o desenvolvimento do gênero humano ainda tem um tom de concessão -, a carta discorre sobre sua concepção de feminilidade.

O que está em disputa aqui é a ideia de mulher que deveria orientar os debates na IV CMM, visando os documentos de status internacional que seriam ali elaborados e sua subsequente influência em políticas públicas. É importante sublinhar que uma declaração do Vaticano sobre a imagem que se quer constituir como hegemônica da mulher e de seu papel na sociedade não se limita à direção religiosa de seus fiéis. Como um ator político, o Vaticano se insere nesse debate concorrendo pela formação de opiniões, bem como apostando na influência que exerce sobre comportamentos e posicionamentos políticos de grupos que se articulam secularmente aos arredores da Igreja Católica.

Na Carta de 1995, a feminilidade é sustentada por um tripé: a afirmação da natureza da mulher, a partir de critérios biológicos e ontológicos; a ideia de complementaridade entre o masculino e o feminino, formando a "unidualidade" 
Teoria de gênero e ideologia de gênero: cenário de uma disputa nos 25 anos da IV Conferência Mundial das Mulheres

Géssica Guimarães

que garantiria a perpetuação da vida e o pleno desenvolvimento do gênio masculino e do gênio feminino, sem nem mesmo negar a desigualdade fundante entre eles; e a "iconicidade", consubstanciada na figura de Maria e das atribuições do feminino para a vida em comunidade. Assim concebida, a feminilidade ganha traços universais e completamente anti-históricos. As características culturais e a historicidade das mulheres são apagadas, e a elas é imposta uma série de atribuições que tem como resultado último o aniquilamento da identidade e de sua realização como sujeito. Isso porque a correlação do feminino com aspectos que intrinsecamente deveriam constituir a atuação das mulheres tais como a sensibilidade, a maternidade, o cuidado com os outros e a conciliação de conflitos e humores novamente reafirma relações de gênero ancoradas na concepção do homem como o sujeito universal e da mulher como o segundo sexo, como teorizou Simone de Beauvoir (1970).

A Conferência de Pequim contou com aproximadamente 50.000 participantes e foi um dos maiores fóruns de debate organizados pela ONU na década de 1990. Cerca de 2/3 dos participantes eram mulheres e os debates prenunciados na Conferência de Cairo sobre os direitos reprodutivos e a importância de compreender as opressões vivenciadas pelas mulheres pela perspectiva das relações de gênero conferiram o diapasão das discussões ${ }^{10}$. Mas os desafios foram muitos, envolveram problemas com o Governo chinês, dificuldades na organização do evento e acomodação das participantes, até a mobilização de muitos grupos contrários às pautas feministas, que se formavam

\footnotetext{
10 Na "Apresentação" da versão brasileira que relata as decisões da Conferência, publicada em 2006, Maria Luiza Ribeiro Viotti, Diplomata e então Ministra e Diretora-geral do Departamento de Direitos Humanos e Temas Sociais do Ministério das Relações Exteriores, nos apresenta uma síntese das principais pautas elencadas em Pequim: "Identificaram-se doze áreas de preocupação prioritária, a saber: a crescente proporção de mulheres em situação de pobreza (fenômeno que passou a ser conhecido como a feminização da pobreza); a desigualdade no acesso à educação e à capacitação; a desigualdade no acesso aos serviços de saúde; a violência contra a mulher; os efeitos dos conflitos armados sobre a mulher; a desigualdade quanto à participação nas estruturas econômicas, nas atividades produtivas e no acesso a recursos; a desigualdade em relação à participação no poder político e nas instâncias decisórias; a insuficiência de mecanismos institucionais para a promoção do avanço da mulher; as deficiências na promoção e proteção dos direitos da mulher; o tratamento estereotipado dos temas relativos à mulher nos meios de comunicação e a desigualdade de acesso a esses meios; a desigualdade de participação nas decisões sobre o manejo dos recursos naturais e a proteção do meio ambiente; e a necessidade de proteção e promoção voltadas especificamente para os direitos da menina." (VIOTTI, 1995, p. 148-149).
} 
desde a repercussão da atuação das mulheres nas conferências anteriores, de Viena (1993) e Cairo (1994) (COSTA, 2003, p. 98-99).

O encontro, considerado uma "vitória" pelas mulheres que se engajaram no debate progressista, teve como encaminhamentos três aspectos centrais que nortearam a Plataforma de Ação de Pequim: o conceito de gênero, a noção de empoderamento das mulheres e o enfoque da transversalidade. Ao defender a utilização do conceito de gênero, o que se pretendia era o afastamento de uma concepção da mulher, do seu corpo e da sua atuação na sociedade marcada por sua condição biológica, abstrata ou universal. A ênfase nas relações de gênero permitia a historicização dos sentidos conferidos social e culturalmente ao feminino e acreditava-se que ao apontar o caráter histórico dessas relações seria possível modificá-las.

Os discursos em prol do empoderamento feminino se tornaram uma importante plataforma de encorajamento da atuação das mulheres, bem como de afirmação da importância de políticas públicas e institucionais como fomento e promoção de condições de possibilidade do desenvolvimento das mulheres e conquista de sua autonomia11. E para tal, o enfoque transversal se mostrou imprescindível, uma vez que as relações de gênero se manifestam em todos os âmbitos da vida, será necessário combater as opressões do sexismo não apenas na vida doméstica, mas no acesso à educação, no exercício dos direitos civis e políticos, na expressão cultural, no mercado de trabalho, na defesa dos direitos reprodutivos, entre outros.

As deliberações da Plataforma de Ação de Pequim não foram bem recebidas por grupos mais conservadores, representados pelo Vaticano, alguns países islâmicos e alguns países da América Latina (COSTA, 2003, p. 100). A partir desses embates, inicia-se uma verdadeira cruzada contra o "gênero", já entendido como ideologia e cuja carga política atingiu notoriedade quando associado aos estudos que problematizam a heteronormatividade compulsória, como a obra da filósofa Judith Butler.

\footnotetext{
${ }^{11}$ Em O ponto zero da revolução, Silvia Federici faz duras críticas às consequências de alguns dos debates encetados na IVCMM, principalmente relativos ao desdobramento neoliberal que algumas práticas pró-empoderamento revelaram. Ver: FEDERICI, Silvia. O ponto zero da revolução. São Paulo: Editora Elefante, 2019
} 
Nesses últimos vinte e cinco anos, desde a realização da IV Conferência Mundial das Mulheres, o conceito de gênero tem sido alvo de disputas. Grupos que se opõem aos horizontes políticos anunciados em Pequim - como a emancipação e o empoderamento das mulheres -, e que se sentem ameaçados pelo crescente movimento contra homofobia e transfobia, têm alimentado uma campanha mundial com o objetivo de afirmar a existência de uma "ideologia de gênero". Nessa batalha, buscam a desqualificação do gênero, seja como categoria ou conceito, atribuindo a ele a adjetivação de "ideologia". Embora esse não seja o escopo deste artigo, vale desde já apontar que o uso que fazem do conceito de ideologia revela um significado bonapartista, isto é, tal como Napoleão Bonaparte o utilizou em ataque aos intelectuais que se manifestaram contra sua política imperialista; empregam o conceito de ideologia como sinônimo de mentira, falseamento ou manipulação da realidade, no qual o critério de averiguação consiste unicamente na oposição política entre os grupos em disputa - ou seja, a alegação de que o discurso do outro é ideológico porque contrário ao seu'12.

No Brasil atual, o termo "ideologia de gênero" ganhou bastante circulação, sobretudo na esteira dos projetos vinculados ao Programa Escola sem Partido (ESP), criado pelo advogado Miguel Nagib, em 2004. Como destaca Fernando Penna, aqueles que defendem propostas para a educação a partir do ESP, entendem a "ideologia de gênero" como "uma ideologia antifamília, uma tentativa de transformar os jovens em gays e lésbicas, um ataque à família." (PENNA, 2018, p. 45).

Também em 2004, o Vaticano lançou um documento intitulado Carta aos Bispos da Igreja Católica sobre a colaboração do homem e da mulher na Igreja e no mundo. Nesse documento, há a sugestão de que as abordagens sobre as relações histórico-sociais que caracterizam os papéis de gênero em cada tempo e espaço seriam uma lente deformadora da realidade e que levariam à disfunção social. Vejamos o que diz o documento:

\footnotetext{
12 Para melhor compreender a questão, sugerimos a leitura de o que é ideologia?, de Marilena Chauí, e A ideologia e a utopia, de Paul Ricoeur. Ver: CHAUí, Marilena de Souza. O que é ideologia? Coleção Primeiros Passos. São Paulo: Editora Brasiliense, 1997 e RICOEUR, Paul. Aula introdutória. In: RICOEUR, Paul. A ideologia e a utopia. Belo Horizonte: Autêntica, 2015.
} 
Uma tal antropologia, que entendia favorecer perspectivas igualitárias para a mulher, libertando-a de todo o determinismo biológico, acabou de facto por inspirar ideologias que promovem, por exemplo, o questionamento da família, por sua índole natural bi-parental, ou seja, composta de pai e de mãe, a equiparação da homossexualidade à heterossexualidade, um novo modelo de sexualidade polimórfica. (VATICANO, 2004).

Essa constatação é seguida de uma longa reflexão sobre "Os dados fundamentais da antropologia bíblica", pelos quais se pretende afirmar nas escrituras sagradas os devidos atributos de homens e mulheres na vida esponsal e comunitária.

Ocorre que os ecos da formulação acerca da existência de uma "ideologia de gênero" ainda se fazem ouvir no Brasil e em outros lugares do mundo. Na proposta de plano de governo de Jair Bolsonaro, candidato eleito presidente do Brasil em outubro de 2018, constam palavras de ordem contra a suposta doutrinação no ensino, que ele propõe que seja combatida "expurgando a ideologia de Paulo Freire", de maneira que "Conteúdo e método de ensino precisam ser mudados. Mais matemática, ciências e português, SEM DOUTRINAÇÃO E SEXUALIZAÇÃO PRECOCE” (BOLSONARO, 2018, grifo do autor). Fica claro como o então candidato pretendia desqualificar as disciplinas associadas às humanidades e os estudos de gênero na proposta referida. Sem qualquer base empírica ou fundamento científico, a plataforma de governo, assim como a campanha eleitoral, lançou mão de inúmeras acusações falsas e sugestões inverossímeis sobre o ensino das relações de gênero nas escolas públicas brasileiras.

O movimento político que ficou conhecido pela hashtag \#EleNão foi uma contundente demonstração de que vários setores da sociedade brasileira não concordavam com as declarações misóginas do candidato do PSL. Contudo, setores mais conservadores da sociedade, como aqueles ligados às igrejas neopentecostais, reagiram de maneira inversa e fortaleceram seu apoio à campanha bolsonarista, buscando reforço para suas pautas como a criminalização do aborto, a proibição do casamento entre pessoas do mesmo sexo e o combate à "ideologia de gênero". 
Em 2 de fevereiro de 2019, o Papa Francisco I assinou um documento intitulado "Homem e mulher os criou" para uma via de diálogo sobre a questão do gender na educação, destinado aos setores da educação católica. Embora o documento seja endereçado às instituições católicas e aos profissionais da educação que atuam em tais escolas, a retórica universalista ainda é uma marca indelével da argumentação da chefia da Igreja Católica. Numa tentativa de forjar o diálogo, como proposto no título do documento, a argumentação parte do reconhecimento da importância dos estudos sobre o gender - a palavra não é traduzida nem para o italiano, nem na versão do documento para o português; a opção deliberada parece apontar para a "setorização” do debate.

Contudo, se por um lado, as investigações sobre o gender são aceitas por "aprofundar adequadamente o modo em que se vive, nas diversas culturas, a diferença sexual entre homem e mulher". Ao longo de todo o documento é afirmada a "visão antropológica cristã", que afirma a relação intrínseca e irrefutável entre sexo e gênero e a concepção da masculinidade e da feminilidade através de sua vocação para a reprodução. Nesse aspecto, não poderíamos deixar de destacar a negação recorrente no documento de vidas e famílias cujos projetos não estejam comprometidos com a reprodução ${ }^{13}$.

\section{Por um ensino de história comprometido com uma sociedade democrática}

Marcelo Magalhães (2009), quando analisou a relação entre história e cidadania nos Parâmetros Curriculares Nacionais (1996) - importante documento que orientou a educação brasileira na primeira década deste século - sublinhou a menção às questões relacionadas ao gênero:

a questão da identidade entra no ensino de história para facilitar o trabalho de construção com os alunos de noções como semelhança/diferença, permanência/mudança e, também a percepção de que no âmbito do social existem processos múltiplos de pertencimento (de gênero, étnico, de classe, de grupos sociais, de Estado Nacional, etc.). (MAGALHÃES, 2009, p. 176).

\footnotetext{
13 Para um aprofundamento da crítica à função social da mulher associada à reprodução da vida, ver Danièle Kergoat: KERGOAT, Danièle. Divisão sexual do trabalho e relações sociais de sexo. In: DICIONÁRIO CRÍTICO DO FEMINISMO. São Paulo: Editora Unesp, 2009.
} 
Concordando com a avaliação de Magalhães, para quem os PCNs valorizam a dimensão histórica para a compreensão do conceito de cidadania, e tomando esse documento como registro de um projeto democrático para a educação nacional, nossa sugestão consiste em que as questões de gênero também sejam abordadas no ensino de história buscando tal densidade temporal e não apenas como uma atribuição da identidade pessoal. Isto é, partindo do tempo presente e das motivações de nossa própria sociedade, transformar a pesquisa do passado na possibilidade de compreender não apenas a genealogia da opressão de gênero, mas principalmente seu traço histórico, através das variadas significações que essas relações adquiriram ao longo do tempo e do espaço.

Daniel Pinha Silva (2017) nos adverte sobre o lugar do tempo presente na sala de aula, refletindo como armadilhas para o pensamento histórico, comumente associadas ao anacronismo, podem ser "controladas". Segundo o historiador, dessa forma seria possível preservar a pertinência do tempo presente nas aulas de história, garantindo que a relação entre professores e estudantes seja permeada por seu próprio tempo e pelas questões que o presente nos traz. Ao nos lembrar de que a história e o aprendizado do passado, desde seu fundamento clássico, tiveram o caráter político acentuado, seja na capacidade de orientação da ação através dos exemplos, seja por meio da construção de um repertório que constituirá a identidade de uma coletividade, o historiador nos encoraja a trazer de volta às discussões curriculares os temas que estão na "ordem do dia".

Nessa operação, as professoras e os professores poderão construir acessos ao passado a partir de experiências cotidianas dos estudantes, de maneira que, ao abordar temas como a violência sistemática contra as mulheres, sejam oferecidas à turma ferramentas para compreender que não se trata de um dado episódico, mas de uma longa duração que envolve relações de poder e dominação que não são estáticas, mas que se transformam historicamente e podem revelar aspectos íntimos de uma dada sociedade.

Em artigo publicado em 2009, a historiadora Luciana Gandelman analisou a publicação dos PCNs e a repercussão dos debates sobre as relações de gênero e a orientação sexual de maneira otimista. Vejamos: 
Antes de mais nada, é preciso reconhecer a importância de encontrarmos dentro de um instrumento que se propõe a servir de base para a organização de um projeto educacional nacional discussões relativas à questão de gênero. Isso reflete, por um lado, as conquistas dos movimentos feministas e, por outro, a importância e ampla aceitação que a categoria de gênero vem ganhando nos meios acadêmicos. (GANDELMAN, 2009, p. 210)

Ora, que transformação se efetivou em uma década a ponto de tornar o discurso da "ideologia de gênero" mais assíduo no debate político do que os estudos de gênero? Talvez um dos aspectos que nos esclareça sobre tal giro esteja contido na conclusão de Gandelman (2009, p. 213) sobre os próprios Parâmetros, uma vez que a abordagem das relações de gênero como tema transversal e não como um conteúdo do ensino de história apontava para uma abordagem psicopedagógica, esvaziada de historicidade e das disputas políticas, e mais aproximada ao âmbito da família e das relações interpessoais.

Marcos Felipe Gonçalves Maia e Damião Rocha (2017), educadores e membros do Observatório de Sistemas e Planos de Educação no Tocantins, analisam o impacto do discurso da "ideologia de gênero" na elaboração do Plano Nacional da Educação (2014-2024), e como os seus defensores buscaram deslegitimar as pesquisas e estudos sobre as relações de gênero, ao afirmarem o domínio do heterossexismo e da subordinação da mulher a instituições como a família e o casamento. Como consequência direta, há um grande silenciamento das questões de gênero e das reivindicações das mulheres por uma sociedade igualitária nos documentos elaborados sob esses ataques.

Priscila Freire (2018) empreende semelhante investigação, mas tendo como escopo de sua observação os debates em torno da terceira versão da Base Nacional Comum Curricular em Manaus; assim como Rafaela Borges e Zulmira Borges (2018) analisaram o recente debate sobre os planos estadual e municipal de educação do Rio Grande do Sul e de Porto Alegre. As pesquisas mencionadas assinalam a emergência de um discurso de "pânico moral" e perseguição de qualquer preceito pedagógico que apontasse para a importância de que as relações de gênero fizessem parte dos conteúdos curriculares. Como consequência, observaram um acanhado espaço para o tratamento das questões 
de gênero tanto na versão final da BNCC para o Ensino Fundamental, como nos Planos de Educação.

A ação do Estado tem se mostrado, ao mesmo tempo, imprescindível para o avanço da transformação da sociedade, bem como ainda pode ser considerada insuficiente para uma mudança efetiva da sociedade patriarcal. Projetos como o ESP (Escola Sem Partido) significam um grande retrocesso em um âmbito ainda muito fechado às reflexões de gênero: a educação escolar. Mesmo o discurso histórico ainda está em vias de transformação pela história das mulheres e pelas epistemologias feministas; bem como o ensino de história ainda apresenta lacunas em relação a ações efetivas de combate às desigualdades de gênero, seja nos livros didáticos ou na estrutura curricular, com especial atenção à BNCC.

A escrita da história e a ciência historiográfica se afirmaram ao longo dos anos como práticas perpetuadoras de concepções sexistas. Historicamente, os primeiros historiadores foram homens, ou pelo menos esta é a história que nos contam, pois até mesmo no interior de uma das principais memórias institucionais sobre o exercício da historiografia no século XX, aquela forjada pela escola francesa dos Annales, a produção feminina tem sido paulatinamente silenciada. Embora estudos recentes tenham destacado a produção intelectual e a atuação profissional de Lucie Varga, por exemplo, ainda assim o cânone parece respeitar aspectos masculinos (YAMASHITA, 2017).

A esse respeito, a dissertação de mestrado de Bruna Stutz Klem, Historiadoras: aproximações femininas à história da historiografia brasileira (19701990), confirma o que foi dito acima, mas tendo como foco a historiografia brasileira, principalmente a produção na área de Teoria da História e História da Historiografia. Klem (2019) constata que mesmo a presença das mulheres enquanto professoras universitárias e a produção historiográfica de autoria feminina reconhecida no campo não são o suficiente para evitar que os principais postos da carreira sejam ocupados por homens, bem como seja mantido até os dias atuais o cânone majoritariamente masculino, sobretudo nas narrativas da história da historiografia brasileira. A historiadora avaliou, inclusive, diversos compêndios publicados nos últimos anos e observou que, embora muitas 
historiadoras componham o rol de autores, os personagens historiografados continuam sendo em sua totalidade masculinos ${ }^{14}$.

No ensino de história, o quadro não é muito distinto do esboçado acima; inúmeras publicações nos últimos cinco anos apontam para a importância da inclusão efetiva do estudo das relações de gênero no ensino de história. Jaqueline Aparecida Martins Zarbato (2015), professora da Universidade Federal de Mato Grosso do Sul, argumenta que a ausência de formação das professoras nesse campo de conhecimento e a carência de materiais didáticos que auxiliem a abordagem em sala de aula têm sido duas grandes dificuldades encontradas entre o grupo de docentes que participaram de sua pesquisa. Nucia Alexandra Silva de Oliveira (2017), Professora da Universidade do Estado de Santa Catarina (Udesc), analisando o resultado da pesquisa intitulada Os jovens e a história, averiguou que a grande maioria das/dos entrevistadas/os reconhece a importância do estudo das relações entre homens e mulheres e a presença das mulheres no estudo da história, pois concebem de maneira positiva a construção de uma sociedade baseada em igualdade de direitos e condições entre homens e mulheres ${ }^{15}$. Contudo, esses mesmos jovens afirmaram que conheciam pouco a atuação das mulheres na história, pois tal assunto não estava presente nas aulas desta disciplina.

Esses são alguns exemplos que nos motivam a acreditar que ainda há muito trabalho a ser feito se quisermos um ensino de história comprometido com uma educação democrática. Nessa direção, a incongruência entre a "teoria de gênero" e a "ideologia de gênero" deve nos servir como um alerta, a fim de que o potencial pedagógico que ainda pode ser ampliado por meio da análise das relações de gênero no ensino de história não seja reprimido.

\footnotetext{
4 Também ver OLIVEIRA, Maria da Glória de. Os sons do silêncio: interpelações feministas decoloniais à história da historiografia. História da Historiografia, v. 11, n. 28, set-dez, p. 104-140, 2018. e VARELLA, Flávia Florentino. Limites, desafios e perspectivas: a primeira década da revista História da Historiografia (2008-2018). História da Historiografia, v. 11, n. 28, set-dez, p. 219-265, 2018.

15 Aqui, apresentamos os resultados da pesquisa, mas fazemos a ressalva para o binarismo implícito na concepção de que as relações de gênero se efetivam sempre entre homens e mulheres.
} 


\section{Referências}

AKOTIRENE, Carla. Interseccionalidade. São Paulo: Sueli Carneiro: Pólen, 2019.

BEAUVOIR, Simone de. O segundo sexo. 4. ed. Difel, 1970.

BOLSONARO, Jair. O caminho da prosperidade: proposta de plano de governo. 2018. Disponível em: https://static.cdn.pleno.news/2018/08/Jair-Bolsonaroproposta_PSC.pdf. Acesso em agosto de 2019.

BORGES, Rafaela Oliveira; BORGES, Zulmira Newlands. Pânico moral e ideologia de gênero articulados na supressão de diretrizes sobre questões de gênero e sexualidade nas escolas. Revista Brasileira de Educação, Rio de Janeiro, v. 23, e230039, 2018. Disponível em:

http://www.scielo.br/scielo.php?script=sci_arttext\&pid=S1413-

24782018000100231\&lng=en\&nrm=iso. Acesso em: agosto de 2019.

BUTLER, Judith. Problemas de gênero: feminismo e subversão da identidade. Rio de Janeiro: Civilização Brasileira, 2015.

CARNEIRO, Aparecida Sueli. A construção do outro como não-ser como fundamento do ser. 2005. Tese (Doutorado em Educação) - Programa de PósGraduação em Educação, Universidade de São Paulo, São Paulo, 2005.

CORRÊA, Sonia. A "política do gênero": um comentário genealógico. Cadernos Pagu, Campinas, n. 53, 2018. Disponível em:

http://www.scielo.br/scielo.php?script=sci_abstract\&pid=S010483332018000200401\&lng=pt\&nrm=iso. Acesso em: agosto de 2019.

COSTA, Grazielle Furtado Alves da. Solidariedade e Soberania nos discursos sobre "mulher" nas Conferências do Cairo e de Beijing. 2003. Dissertação (Mestrado em Relações Internacionais) - Pontifícia Universidade Católica do Rio de Janeiro, Rio de Janeiro, 2003.

COSTA, Suely Gomes. Gênero e história. IN: ABREU, Marta; SOIHET, Rachel. Ensino de história: conceitos, temáticas e metodologias. Rio de Janeiro: Casa da palavra, 2009.

DAVIS, Angela. Mulheres, raça e classe. São Paulo: Boitempo, 2016.

FEDERICI, Silvia. Calibã e a bruxa: mulheres, corpo e acumulação primitiva. São Paulo: Editora Elefante, 2017.

FRAZÃO, Felipe. Bolsonaro recebe apoio de líderes evamgélicos. IN: O Estado de São Paulo. São Paulo, 01 de outubro de 2018. Disponível em: https://politica.estadao.com.br/noticias/eleicoes,bolsonaro-recebe-apoio-delideres-evangelicos,70002527014 Acesso em: 20 de abril de 2020. 
FREIRE, Priscila. 'Ideologia de gênero' e a política de educação no Brasil: exclusão e manipulação de um discurso heteronormativo”. Ex æquo, n. 37, p. 33-46, 2018. Disponível em:

http://www.scielo.mec.pt/scielo.php?script=sci_abstract\&pid=S087455602018000100004\&lng=pt\&nrm=iso. Acesso em: agosto de 2019.

GANDELMAN, Luciana M. Gênero e ensino: parâmetros curriculares, fundacionalismo biológico e teorias feministas. In: ABREU, Marta; SOIHET, Rachel. Ensino de história: conceitos, temáticas e metodologias. Rio de Janeiro: Casa da palavra, 2009.

HOOKS, bell. O feminismo é para todo mundo. Rio de Janeiro: Rosa dos tempos, 2018.

KLEM, Bruna Stutz. Historiadoras: aproximações femininas à história da historiografia brasileira (1970-1990). Dissertação (Mestrado em História) Universidade Federal de Ouro Preto, Ouro Preto, 2019.

MAIA, Marcos Felipe Gonçalves; ROCHA, Damião. Ideologia de gênero: tensões e desdobramentos na educação. Revista Contemporânea de Educação, v. 12, n. 25, pp. 402-419, set./dez. de 2017. Disponível em: https://revistas.ufrj.br/index.php/rce/article/view/3690. Acesso em: agosto de 2019.

MARAFON, Giovanna; SOUZA, Marina Castro e. Como o discurso da "ideologia de gênero" ameaça o caráter democrático e plural da escola? In: PENNA, Fernando. QUEIROZ, Felipe; FRIGOTTO, Gaudêncio. Educação democrática: antídoto ao escola sem partido. Rio de Janeiro: UERJ: LPP, 2018.

MAGALHÃES, Marcelo de Souza. História e cidadania: porque ensinar história hoje? In: ABREU, Marta; SOIHET, Rachel. Ensino de história: conceitos, temáticas e metodologias. Rio de Janeiro: Casa da palavra, 2009.

OLIVEIRA, Maria da Glória de. Os sons do silêncio: interpelações feministas decoloniais à história da historiografia. História da Historiografia, v. 11, n. 28, p. 104-140, set./dez., 2018. Disponível em:

https://www.historiadahistoriografia.com.br/revista/article/view/1414. Acesso em: agosto de 2019.

OLIVEIRA, Nucia Alexandra Silva de. Ensino de história e questões de gênero: observações a partir do Projeto 'Os Jovens e a História'. Revista História Hoje, v. 6, n. 12, p. 231-249, 2017. Disponível em:

https://rhhj.anpuh.org/RHHJ/article/view/383. Acesso em: agosto de 2019.

PENNA, Fernando de Araujo. O Escola sem Partido como chave de leitura do fenômeno educacional. IN: FRIGOTTO, Gaudêncio (org.). Escola "sem" Partido: esfinge que ameaça a educação e a sociedade brasileira. Rio de Janeiro: UERJ: LPP, 2017. 
RIBEIRO, Djamila. O que é lugar de fala? Belo Horizonte: Letramento: Justificando, 2017.

ROSSI, Amanda; CARNEIRO, Julia Dias; GRAGNANI, Juliana Gragnani. \#EleNão: A manifestação histórica liderada por mulheres no Brasil vista por quatro ângulos. IN: BBC News Brasil. São Paulo, 30 de setembro de 2018. Disponível em https://www.bbc.com/portuguese/brasil-45700013 Acesso em: 20 de abril de 2020.

SCOTT, Joan. Gender: Still a Useful Category of Analysis? Diogenes, v. 57, n. 7, 2010. Disponível em: https://sites.duke.edu/his180/files/2014/08/Scott_GenderStill-a-Useful-Category-of-Analysis.pdf. Acesso em: agosto de 2019.

SCOTT, Joan. Gênero: uma categoria útil para a análise histórica. Educação e Realidade. v. 20, n.2, pp. 71-99, jul-dez, 1995. Disponível em: https://seer.ufrgs.br/educacaoerealidade/article/view/71721/40667. Acesso em: agosto de 2019.

SCOTT, Joan. História das mulheres. In: BURKE. Peter. A escrita da história: novas perspectivas. São Paulo: Editora UNESP, 1992. p. 63-95.

SILVA, Daniel Pinha. O lugar do tempo presente na aula de história: limites e possibilidades. Revista Tempo e Argumento, Florianópolis, v. 9, n. 20, p. 99-129, jan./abr. 2017. Disponível em:

http://www.revistas.udesc.br/index.php/tempo/article/view/21751803092020170 99. Acesso em: agosto de 2019.

VARELLA, Flávia Florentino. Limites, desafios e perspectivas: a primeira década da revista História da Historiografia (2008-2018). História da Historiografia, v. 11, n. 28, p. 219-265, set./dez. 2018. Disponível em:

https://www.historiadahistoriografia.com.br/revista/issue/view/31. Acesso em: agosto de 2019.

VATICANO. Carta aos Bispos da Igreja Católica sobre a colaboração do homem e da mulher na igreja e no mundo. 2004. Disponível em:

https://www.vatican.va/roman_curia/congregations/cfaith/documents/rc_con_cf aith_doc_20040731_collaboration_po.html. Acesso em: agosto de 2019.

VATICANO. Carta do Papa João Paulo II às mulheres. 1995. Disponível em: http://www.vatican.va/content/john-paul-ii/pt/letters/1995/documents/hf_jpii_let_29061995_women.html. Acesso em: agosto de 2019.

VATICANO. Homem e mulher os criou" para uma via de diálogo sobre a questão do gender na educação. 2019. Disponível em:

https://www.vatican.va/roman_curia/congregations/ccatheduc/documents/rc_c on_ccatheduc_doc_20190202_maschio-e-femmina_po.pdf. Acesso em: agosto de 2019. 
VIOTTI, Maria Luiza Ribeiro. Apresentação. IN: DECLARAÇÃO E PLATAFORMA DE AÇÃO DA IV CONFERÊNCIA MUNDIAL SOBRE A MULHER. Pequim, 1995.

Disponível em: http://www.onumulheres.org.br/wpcontent/uploads/2013/03/declaracao_beijing.pdf. Acesso em: agosto de 2019.

YAMASHITA, Jougi Guimarães. Lucie Varga: a "desconhecida" historiadora dos Annales. In: Café História: história feita com cliques. Brasília, 03 jul. 2017. Disponível em: https://www.cafehistoria.com.br/lucie-varga-e-os-annales/. Acesso em: 10 abr. 2019.

ZARBATO, Jaqueline Aparecida Martins. As estratégias do uso do Gênero no ensino de História: narrativa histórica e formação de professoras. Revista Trilhas da História, Três Lagoas, v.4, n.8, jan./jun., p.49-65, 2015. Disponível em: https://periodicos.ufms.br/index.php/RevTH/article/view/694. Acesso em: agosto de 2019. 